\title{
Pengaruh Orientasi Pasar Terhadap Kinerja Konveksi Tekstil Jakarta Barat Dengan Orientasi Kewirausahaan Sebagai Variabel Mediasi
}

\author{
Caroline Susanto dan Lydiawati Soelaiman \\ Program Studi Manajemen, Fakultas Ekonomi dan Bisnis \\ Universitas Tarumanagara, Jakarta \\ Email: ccarolinesusanto@gmail.com
}

\begin{abstract}
This research was conducted to determine and understand the impact of market orientation on the performance of textile convection in West Jakarta, mediated by entrepreneurial orientation. This study uses a questionnaire as a tool to collect data needed in research. 42 respondents participated in this research, data analysis using PLS-SEM method using SmartPLS Software version 3.0. Based on the result of data analysis, it was found that market orientation is a significant influence on entrepreneurial orientation, entrepreneurial orientation is a significant effect on performance, but market orientation doesn't significantly influence performance, and entrepreneurial orientation has a moderating effect on the impact of market orientation on performance.
\end{abstract}

Keywords: Market Orientation, Entrepreneurial Orientation, Performance.

Abstrak: Penelitian ini dilakukan untuk mengetahui dan memahami dampak orientasi pasar terhadap kinerja konveksi tekstil di Jakarta Barat, yang dimediasi oleh orientasi kewirausahaan. Penelitian ini menggunakan kuesioner sebagai alat untuk mengumpulkan data yang dibutuhkan dalam penelitian. 42 responden berpartisipasi dalam penelitian ini, analisis data menggunakan metode PLS-SEM menggunakan SmartPLS Software versi 3.0. Berdasarkan hasil analisis data, ditemukan bahwa orientasi pasar berpengaruh signifikan terhadap orientasi wirausaha, orientasi wirausaha berpengaruh signifikan terhadap kinerja, tetapi orientasi pasar tidak berpengaruh signifikan terhadap kinerja, dan orientasi wirausaha memiliki pengaruh moderasi pada dampak orientasi pasar terhadap kinerja.

Kata Kunci: Orientasi Pasar, Orientasi Kewirausahaan, Kinerja.

\section{LATAR BELAKANG}

Manufaktur merupakan penopang utama dalam perkembangan industri yang ada di sebuah negara. Industri manufaktur di Indonesia mulai bangkit kembali, hal ini dapat dilihat dari beberapa produk yang berhasil menguasai pangsa pasar dunia. Menurut Hartanto agar Indonesia menjadi negara dengan industri yang kuat dan maju, maka setidaknya kontribusi industri manufaktur adalah $40 \%$ terhadap PDB. Kinerja industri manufaktur perlu menjadi perhatian agar dapat memberikan sumbangsih bagi perekonomian Indonesia. Untuk meningkatkan kinerja perusahaan, diperlukan strategi yang mendukung agar tercapainya tujuan dengan mengadopsi orientasi kewirausahaan dan orientasi pasar (Ricardo et al., 2014).

Menurut Lumpkin dan Dess (1996) orientasi kewirausahaan dianggap sebagai model, praktek, dan gaya pengambilan keputusan dalam mencari peluang di pasar baru. Perusahaan yang menjalankan orientasi kewirausahaan memiliki kemampuan untuk 
mengubah ketidakpastian lingkungan menjadi keuntungan perusahaan. Menurut Zhou et al. (2007) orientasi pasar merupakan strategi bisnis yang menyeluruh. Orientasi pasar didefinisikan sebagai proses dimana kebutuhan pelanggan dapat terpuaskan dan adanya kebutuhan yang berkelanjutan (Frishmmar \& Horte, 2007). Slater dan Narver (1995) menyimpulkan bahwa orientasi kewirausahaan dapat dianggap sebagai pelengkap penting dari orientasi pasar karena perusahaan memerlukan integrasi dan implementasi kedua orientasi ini agar dapat mencapai tingkat yang lebih tinggi dari pendapatan usaha dan inovasi.

Berdasarkan latar belakang yang telah diuraikan, terdapat beberapa rumusan masalah antara lain: (1) Apakah orientasi pelanggan dapat mempengaruhi orientasi kewirausahaan? (2) Apakah orientasi pesaing dapat mempengaruhi orientasi kewirausahaan? (3) Apakah koordinasi interfunctional dapat mempengaruhi orientasi kewirausahaan? (4) Apakah orientasi kewirausahaan dapat mempengaruhi kinerja?

Berdasarkan rumusan masalah yang ada, tujuan dari penelitian ini adalah untuk mengetahui secara empiris tentang: (1) Untuk mengetahui apakah orientasi pasar mempengaruhi orientasi kewirausahaan konveksi tekstil Jakarta Barat secara signifikan, (2) Untuk mengetahui apakah orientasi kewirausahaan mempengaruhi kinerja konveksi tekstil Jakarta Barat secara signifikan, (3) Untuk mengetahui apakah orientasi pasar mempengaruhi kinerja konveksi tekstil Jakarta Barat secara signifikan, (4) Untuk mengetahui apakah orientasi kewirausahaan mampu memediasi pengaruh orientasi pasar dan kinerja pada industri konveksi tekstil di Jakarta Barat.

\section{KAJIAN TEORI}

Menurut Richard et al. (2009) kinerja organisasi adalah seputar konseptualisasi multidimensi yang didominasi oleh pemangku kepentingan, keadaan pasar yang bersifat heterogen dan waktu. Pengukuran suatu kinerja perusahaan dapat dilihat dari segi keuangan dan non keuangan. Menurut Miller (1983) perusahaan harus berorientasi kewirausahaan apabila ingin meningkatkan keberhasilan usahanya karena orientasi kewirausahaan merupakan pelopor untuk mewujudkan pertumbuhan ekonomi perusahaan yang berkelanjutan, meningkatkan kinerja usaha dan pendekatan baru dalam pembaruan kinerja, memiliki daya saing yang tinggi, dan berperan dalam kesuksesan. Menurut Zhou et al. (2008) orientasi pasar merupakan orientasi yang sangat bernilai dan tidak dapat ditiru dengan sempurna dikarenakan orientasi pasar dinilai dapat menciptakan keunggulan bersaing.

Menurut Narver dan Slater (1990) orientasi pasar terdiri dari 3 komponen perilaku yaitu orientasi pelanggan, orientasi pesaing, dan koordinasi interfunctional. Dimana orientasi pelanggan dan orientasi pesaing merupakan dua pendekatan yang berbeda dan dapat menyebabkan keunggulan kompetitif (Hari \& Wensley, 1988). Secara konseptual baik orientasi pelanggan maupun orientasi pesaing memiliki peran yang sama penting (Zhou et al., 2007). Tujuan umum dari orientasi pelanggan menurut Narver dan Slater (1990) yaitu untuk memberikan dasar kecerdasan yang berkaitan dengan pelanggan saat ini dan masa depan. Tujuan dari orientasi pesaing adalah untuk memberikan dasar kecerdasan yang berkaitan dalam menyajikan potensial bersaing untuk tindakan eksekutif.

$\mathbf{H}_{1}$ : Orientasi Pasar (Orientasi Pelanggan dan Orientasi Pesaing) berpengaruh secara signifikan terhadap Orientasi Kewirausahaan 
Hult dan Ketchen (2001) serta Morris et al. (2002) menyimpulkan bahwa orientasi pasar dan orientasi kewirausahaan adalah sumber daya penting dalam organisasi. Menurut Sciascia et al. (2006 dalam Mantok et al., 2018) menyatakan bahwa orientasi pasar sebagai penentu yang paling relevan untuk orientasi kewirausahaan karena dapat membantu dalam memperkenalkan dan meningkatkan inovasi untuk memenuhi persyaratan yang berkembang dari pelanggan.

$\mathbf{H}_{\mathbf{2}}$ : Orientasi Kewirausahaan berpengaruh secara signifikan terhadap Kinerja

Orientasi kewirausahaan menunjukkan pengaruh yang signifikan terhadap kinerja perusahaan (Nur et al., 2014). Hubungan yang baik antara orientasi kewirausahaan dengan kinerja bisnis dapat meningkatkan kinerja suatu perusahaan. Temuan tersebut didukung dengan adanya studi dari Jim Andersen (2010 dalam Nur et al., 2014) yaitu kinerja perusahaan yang baik dipengaruhi oleh orientasi kewirausahaan.

$\mathbf{H}_{3}$ : Orientasi Pasar (Orientasi Pelanggan dan Orientasi Pesaing) berpengaruh secara signifikan terhadap Kinerja

Menurut Appiah Adu Kwaku (1997 dalam Nur et al., 2014) yang menyatakan bahwa terdapat pengaruh dari orientasi pasar terhadap kinerja perusahaan. Menurut hasil penelitian dari Amir Grinstein (2008) mendukung adanya efek positif dari orientasi pasar terhadap kinerja perusahaan dalam meta-analisis.

$\mathbf{H}_{\mathbf{4}}$ : Orientasi Kewirausahaan akan memediasi hubungan antara Orientasi Pasar (Orientasi Pelanggan dan Orientasi Pesaing) dan Kinerja

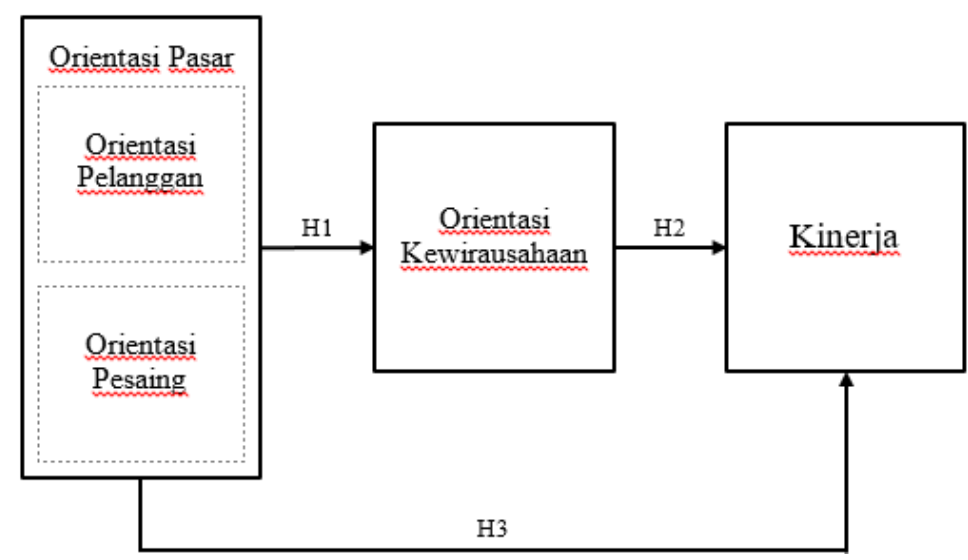

\section{METODOLOGI}

Pendekatan penelitian yang dipakai dalam penelitian ini adalah pendekatan kuantitatif. Berdasarkan karakteristik masalah, penelitian ini termasuk metode penelitian deskriptif. Penelitian ini ditujukan untuk melihat adanya hubungan antara 3 variabel yaitu pengaruh orientasi pasar terhadap kinerja konveksi tekstil di Jakarta Barat dengan orientasi kewirausahaan sebagai variabel mediasi. Teknik yang digunakan adalah convenience sampling. Jumlah sampel dalam penelitian ini adalah 42 sampel, dengan karakteristik 
responden berdasarkan usia usaha dan jumlah karyawan. Teknik pengumpulan data dalam penelitian ini menggunakan kuesioner.

Penelitian ini menggunakan teknik analisis data Structural Equation Modelling (SEM), dengan Variance-Based (PLS-SEM) dan menggunakan bantuan perangkat lunak SmartPLS Versi 3.0. SEM membagi menjadi dua bagian yaitu outer model dan inner model. Analisis validitas dan reliabilitas merupakan bagian dari outer model, yang diukur dengan menggunakan convergent validity, discriminant validity, dan uji reliabilitas. Inner model analysis dapat dilakukan hanya apabila seluruh variabel dan indikator yang digunakan untuk penelitian telah memenuhi lolos uji validitas dan reliabilitas.

Dalam pengujian hipotesis terdapat dua kemungkinan yang dapat terjadi terhadap hipotesis penelitian yaitu hipotesis tersebut ditolak atau diterima. Hipotesis penelitian dinyatakan signifikan atau dapat diterima apabila nilai T-Statistik yang muncul lebih dari 1,96 dan nilai P-Values tidak melebihi 0,05.

\section{HASIL ANALISIS DATA}

Dari 42 responden, diantaranya terdapat 19 pemilik konveksi tekstil berusia di bawah 5 tahun $(45.2 \%)$. Sisanya, sebanyak 12 pemilik konveksi tekstil berusia 5 sampai 10 tahun (28.6\%), dan 11 pemilik konveksi tekstil berusia di atas 10 tahun (26.2\%). Dan, terdapat 31 pemilik konveksi tekstil memiliki jumlah karyawan sebanyak kurang dari 50 orang $(73.9 \%)$. Sisanya, sebanyak 8 pemilik konveksi tekstil memiliki jumlah karyawan sebanyak 50 - 100 orang, dan 3 pemilik konveksi tekstil memiliki jumlah karyawan sebanyak di atas 100 orang.

Hasil analisis convergent validity ditunjukkan oleh Tabel 1, sementara untuk hasil analisis discriminant validity dan uji reliabilitas ditunjukkan oleh Tabel 2. Tabel 3 menunjukkan hasil analisis Average Variance Extracted, composite reliability. Berdasarkan hasil analisis convergent validity, reliabilitas, dan discriminant validity, dapat disimpulkan bahwa seluruh variabel di dalam penelitian ini yakni Orientasi Pasar, Orientasi Kewirausahaan, dan Kinerja telah memenuhi syarat validitas dan reliabilitas.

Berdasarkan hasil analisis $\mathrm{R}^{2}$, variabel orientasi pelanggan sebesar 0.716 yang artinya adalah sebesar $71.6 \%$ orientasi pelanggan dapat dijelaskan oleh orientasi orientasi pasar, sementara sisanya $28.4 \%$ dapat dijelaskan oleh variabel lainnya di luar penelitian ini. Orientasi Pesaing memiliki nilai $\mathrm{R}^{2}$ sebesar 0.902 . Artinya, sebesar $90.2 \%$ variabel orientasi pesaing dapat dijelaskan oleh orientasi pasar, sementara sisanya $9.8 \%$ dapat dijelaskan oleh variabel lainnya di luar penelitian ini. Nilai $\mathrm{R}^{2}$ untuk orientasi kewirausahaan adalah sebesar 0.613 yang mempunyai arti bahwa sebesar $61.3 \%$ variabel orientasi kewirausahaan dapat dijelaskan oleh orientasi pasar, sementara sisanya $38.7 \%$ dapat dijelaskan oleh variabel lainnya di luar penelitian ini. Kinerja memiliki nilai $\mathrm{R}^{2}$ sebesar 0.589 . Artinya, sebesar $58.9 \%$ variabel kinerja dapat dijelaskan oleh orientasi kewirausahaan, sementara sisanya $41.1 \%$ dapat dijelaskan oleh variabel lainnya di luar penelitian ini.

Berdasarkan hasil analisis $\mathrm{Q}^{2}$ di atas, nilai $\mathrm{Q}^{2}$ untuk orientasi pelanggan adalah sebesar 0.311 yang artinya variabel tersebut memiliki pengaruh sedang atau moderat dalam memprediksi model. Nilai $\mathrm{Q}^{2}$ untuk orientasi pesaing sebesar 0.541 artinya memiliki pengaruh yang kuat dalam memprediksi model dengan baik. Nilai $\mathrm{Q}^{2}$ untuk orientasi kewirausahaan sebesar 0.295 yang artinya memiliki pengaruh sedang atau moderat dalam memprediksi model, sebaliknya dengan kinerja memiliki pengaruh yang kuat dalam memprediksi model karena nilai $\mathrm{Q}^{2}$ sebesar 0.421. 
Hasil dari penelitian ini mendapatkan nilai 0,6668 yang berarti tingkat kelayakan atas model penelitian dikatakan besar berdasarkan teori Tenenhaus (2004). Nilai $t$-statistics dari pengaruh orientasi pasar terhadap orientasi kewirausahaan memenuhi syarat signifikan, dengan demikian $\mathrm{H} 1$ diterima. Nilai $t$-statistics dari pengaruh orientasi kewirausahaan terhadap kinerja memenuhi syarat signifikan, dengan demikian $\mathrm{H} 2$ diterima. Nilai $t$-statistics dari pengaruh orientasi pasar terhadap kinerja tidak memenuhi syarat signifikan, dengan demikian H3 ditolak. Nilai t-statistics dari pengaruh orientasi kewirausahaan sebagai variabel mediasi antara orientasi pasar dengan kinerja memenuhi syarat signifikan, dengan demikian $\mathrm{H} 4$ diterima.

\section{DISKUSI}

Berdasarkan hasil analisis, maka dapat disimpulkan bahwa (H1) orientasi pasar terbukti memiliki pengaruh signifikan terhadap orientasi kewirausahaan, (2) orientasi kewirausahaan terbukti memiliki pengaruh signifikan terhadap kinerja, (3) orientasi pasar terbukti tidak memiliki pengaruh signifikan terhadap kinerja, (4) orientasi kewirausahaan terbukti dapat menjadi variabel mediasi antara orientasi pasar dengan kinerja.

Berdasarkan penelitian yang telah dilakukan, peneliti menyarankan untuk pemilik konveksi tekstil sebaiknya lebih mempersiapkan diri dengan adanya ancaman pesaing agar dapat merespon tindakan pesaing yang dapat mengancam perusahaan dan faktor luar seperti pemerintah, ekonomi negara, dan peraturan negara. Selain itu, melakukan diskusi secara rutin dengan para tim manajemen puncak sangatlah penting guna memperkuat strategi yang ada untuk mencapai keunggulan kompetitif dan berani dalam mengambil resiko yang ada dengan tujuan agar dapat meningkatkan peluang yang lebih jauh lagi.

Tabel 1. Hasil Analisis Convergent Validity (outer loadings)

\begin{tabular}{|c|c|c|c|}
\hline \multicolumn{2}{|c|}{ Hasil } & Nilai Kritis & Evaluasi Model \\
\hline \multicolumn{3}{|c|}{ Outer Model } & \\
\hline Indikator OP & Loadings & & \\
\hline OP 1 & 0.507 & \multirow{5}{*}{$>0.5$} & Valid \\
\hline OP 2 & 0.821 & Valid \\
\hline OP 3 & 0.824 & Valid \\
\hline OP 4 & 0.743 & & Valid \\
\hline OP 5 & 0.808 & \multirow{5}{*}{} & Valid \\
\hline OP 6 & 0.819 & & Valid \\
\hline OP 7 & 0.925 & & \\
& & & \\
\hline
\end{tabular}


Susanto dan Soelaiman: Pengaruh Orientasi Pasar Terhadap Kinerja Konveksi Tekstil...

\begin{tabular}{|c|c|c|c|}
\hline Indikator OK & Loadings & & \\
\hline OK 1 & 0.654 & \multirow{6}{*}{$>0.5$} & Valid \\
\hline OK 2 & 0.807 & & Valid \\
\hline OK 3 & 0.759 & & Valid \\
\hline OK 4 & 0.816 & & Valid \\
\hline OK 5 & 0.743 & & Valid \\
\hline OK 6 & 0.579 & & Valid \\
\hline \multicolumn{2}{|c|}{ Hasil } & Nilai Kritis & Evaluasi Model \\
\hline \multicolumn{4}{|l|}{ Outer Model } \\
\hline OK 7 & 0.806 & \multirow{2}{*}{$>0.5$} & Valid \\
\hline OK 8 & 0.824 & & Valid \\
\hline Indikator $\mathbf{K}$ & Loadings & & \\
\hline K 1 & 0.942 & $>0.5$ & Valid \\
\hline K 2 & 0.950 & & Valid \\
\hline K 3 & 0.878 & & Valid \\
\hline
\end{tabular}

Tabel 2. Hasil Analisis Discriminant Validity (cross loadings)

\begin{tabular}{|l|c|c|c|c|c|}
\hline & $\begin{array}{c}\text { Orientasi } \\
\text { Pelanggan }\end{array}$ & $\begin{array}{c}\text { Orientasi } \\
\text { Pesaing }\end{array}$ & $\begin{array}{c}\text { Orientasi } \\
\text { Pasar }\end{array}$ & $\begin{array}{c}\text { Orientasi } \\
\text { Kewirausahaan }\end{array}$ & Kinerja \\
\hline OP 1 & $\mathbf{0 . 5 0 7}$ & 0.152 & 0.311 & 0.176 & 0.255 \\
\hline OP 2 & $\mathbf{0 . 8 2 1}$ & 0.528 & 0.704 & 0.638 & 0.632 \\
\hline OP 3 & $\mathbf{0 . 8 2 4}$ & 0.591 & 0.738 & 0.504 & 0.603 \\
\hline OP 4 & 0.499 & $\mathbf{0 . 7 4 3}$ & 0.71 & 0.301 & 0.517 \\
\hline OP 5 & 0.465 & $\mathbf{0 . 8 0 8}$ & 0.751 & 0.539 & 0.558 \\
\hline OP 6 & 0.458 & $\mathbf{0 . 8 1 9}$ & 0.752 & 0.433 & 0.565 \\
\hline OP 7 & 0.663 & $\mathbf{0 . 9 2 5}$ & 0.909 & 0.593 & 0.692 \\
\hline
\end{tabular}


Susanto dan Soelaiman: Pengaruh Orientasi Pasar Terhadap Kinerja Konveksi Tekstil...

\begin{tabular}{|c|c|c|c|c|c|}
\hline OK 1 & 0.406 & 0.455 & 0.481 & $\mathbf{0 . 6 5 4}$ & 0.611 \\
\hline & $\begin{array}{c}\text { Orientasi } \\
\text { Pelanggan }\end{array}$ & $\begin{array}{c}\text { Orientasi } \\
\text { Pesaing }\end{array}$ & $\begin{array}{c}\text { Orientasi } \\
\text { Pasar }\end{array}$ & $\begin{array}{c}\text { Orientasi } \\
\text { Kewirausahaan }\end{array}$ & Kinerja \\
\hline OK 2 & 0.611 & 0.544 & 0.625 & $\mathbf{0 . 8 0 7}$ & 0.567 \\
\hline OK 3 & 0.616 & 0.440 & 0.556 & $\mathbf{0 . 7 5 9}$ & 0.573 \\
\hline OK 4 & 0.645 & 0.527 & 0.626 & $\mathbf{0 . 8 1 6}$ & 0.525 \\
\hline OK 5 & 0.473 & 0.559 & 0.581 & $\mathbf{0 . 7 4 3}$ & 0.633 \\
\hline OK 6 & 0.462 & 0.399 & 0.461 & $\mathbf{0 . 5 7 9}$ & 0.348 \\
\hline OK 7 & 0.514 & 0.68 & 0.678 & $\mathbf{0 . 8 0 6}$ & 0.624 \\
\hline OK 8 & 0.613 & 0.624 & 0.680 & $\mathbf{0 . 8 2 4}$ & 0.624 \\
\hline K 1 & 0.634 & 0.580 & 0.661 & 0.762 & $\mathbf{0 . 9 4 2}$ \\
\hline K 2 & 0.590 & 0.532 & 0.610 & 0.684 & $\mathbf{0 . 9 5 0}$ \\
\hline K 3 & 0.581 & 0.466 & 0.561 & 0.643 & $\mathbf{0 . 8 7 8}$ \\
\hline
\end{tabular}

Tabel 3. Hasil Analisis Average Variance Extracted, Composite Reliability

\begin{tabular}{|c|c|c|c|c|}
\hline Variabel & AVE & Composite Reliability & $\begin{array}{l}\text { Nilai } \\
\text { Kritis }\end{array}$ & $\begin{array}{c}\text { Evaluasi } \\
\text { Model }\end{array}$ \\
\hline Orientasi Pelanggan & 0.536 & 0.769 & \multirow{5}{*}{$>0.60$} & \multirow{5}{*}{ Reliabel } \\
\hline Orientasi Pesaing & 0.683 & 0.895 & & \\
\hline Orientasi Pasar & 0.514 & 0.875 & & \\
\hline Orientasi Kewirausahaan & 0.567 & 0.912 & & \\
\hline Kinerja & 0.854 & 0.946 & & \\
\hline
\end{tabular}

\section{DAFTAR PUSTAKA}

Day, G. a. (1988). Assessing advantage: A framework for diagnosing competitive superiority. Journal of Marketing, Vol. 52 No. 2, 1-20.

Grinstein, A. (2008). The relationships between market orientation and alternative strategic orientations A meta-analysis. European Journal of Marketing Vol. 42 No. 1/2, 115134. 
Horte, J. F. (2007). The role of market orientation and entrepreneurial orientation for new product development performance in manufacturing firms. Technology Analysis \& Strategic Management, 765-788.

JR., G. T. (2001). Does market orientation matter?: A test of the relationship between positional advantage and performance. Strategic Management Journal, 899-906.

Kevin Zheng Zhou, J. R. (2007). The effect of customer and competitor orietations on performance in global markets: a contigency analysis. Journal of International Business Studies, 303-319.

Lumpkin, G. T. (1996). Clarifying the entrepreneurial orientation construct and linking it to performance. Academy of Management Review Vol. 21 No. 1, 135-172.

Michael H. Morris, M. S. (2002). Entrepreneurial Marketing: A construct for integrating emerging entrepreneurship and marketing perspective. The Journal of Marketing Theory and Practice, 1-19.

Miller, D. (1983). The correlates of entrepreneurship in three types of firms. Management Science, Vol. 29 No. 7, 770-791.

Narver, J. a. (1990). The effect of a market orientation on business profitability. Journal of Marketing, Vol. 54 No. 4, 20-35.

Nofal Nur, S. U. (2014). Entrepreneurship orientation, market orientation, business strategy, management capabilities on business performance; study at small and medium enterprise printing in kendari. International Journal of Business and Management Invention Volume 3 Issue 12, 8-17.

Ricardo Garcia Ramirez, G. M. (2014). The relationship between market orientation, entrepreneurial orientation, and innovation: Evidence from Mexican SMEs. Journal of Business and Economics Vol. 5 No. 10, 1930-1940.

Slater, S. a. (1995). Marketing orientation and the learning organisational. Journal of Marketing, Vol. 59 No. 3, 63-75.

Stanzin Mantok, H. S. (2018). Entrepreneurial orientation and the mediating role of organisational learning amongst Indian S-SMEs. Journal of Small Business and Enterprise Development, 1462-6004.

Zhou, K. Z. (2008). Market orientation, competitive advantage, and performance: A demand-based perspective. Journal of Business Research 62, 1062-1070. 